\title{
La Recaudación Del Impuesto Predial En El Municipio De Chihuahua: Un Análisis De Las Causas Del Rezago
}

\author{
Pedro Javier Martínez Ramos (PhD) \\ Martín Venegas Baeza (MBA) \\ Hilda Cecilia Escobedo Cisneros (MBA) \\ Myrna Isela García Bencomo (PhD) \\ Universidad Autónoma de Chihuahua, Mexico
}

Doi:10.19044/esj.2018.v14n19p45 URL:http://dx.doi.org/10.19044/esj.2018.v14n19p45

\begin{abstract}
In order to determine the main reasons for the lag in the payment of the Property Tax of the Municipality of Chihuahua and to ascertain if there is a culture of nonpayment in the taxpayers, an investigation was carried out in this regard. The hypothesis proposed was that the main reason for the lag in the payment of the property tax was the lack of economic resources. The nature of the research was quantitative, descriptive, non-experimental, and transectional. The macro variable to be analyzed was lagged in the payment of taxes. The sampling frame was confirmed by the list of taxpayer debtors of the property tax. A confidence level of $95 \%$ and margin of error of 5\% was used in the study. This, however, was drawn from a sample of 375 contributors to whom the survey designed by the researchers was applied. These were applied randomly in a shopping center in the city. The stated objectives were met and it was found that $6 \%$ of respondents have a culture of non-payment, while $94 \%$ plan to pay. The major reason the taxpayer debtors could not pay the tax was attributed to the lack of economic resources. As a result, the hypothesis was not rejected.
\end{abstract}

Keywords: Lag in payment of taxes, property tax, taxpayers

\section{Resumen}

A fin de determinar las principales razones del rezago en el pago del Impuesto Predial del Municipio de Chihuahua y determinar si existe una cultura de no pago en los contribuyentes, se llevó a cabo una investigación al respecto. La hipótesis planteada fue que la principal razón de rezago en el pago del impuesto predial es la falta de recursos económicos. La naturaleza de la 
investigación fue cuantitativa, descriptiva, no experimental y transeccional; la macrovariable a analizar fue rezago en pago de impuestos, y el marco muestral estuvo conformado por la lista de contribuyentes deudores del impuesto predial. Se utilizó un nivel de confianza de $95 \%$ y margen de error del 5\% a partir de una muestra de 375 contribuyentes a los cuales se les aplicó la encuesta diseñada por los investigadores; ésta fue aplicada aleatoriamente en un centro comercial de la ciudad. Se cumplió con los objetivos planteados y se encontró que el $6 \%$ de los encuestados tiene una cultura de no pago, mientras que el $94 \%$ tiene pensado pagar. La principal causa por la cual los contribuyentes deudores no pagan el impuesto es falta de recursos económicos, por lo que no se rechazó la hipótesis planteada.

Palabras clave: Rezago en pago de impuestos, Impuesto Predial, Contribuyentes

\section{INTRODUCCIÓN}

El impuesto predial es un tributo con el cual se grava una propiedad o posesión inmobiliaria. Es una contribución que hacen los ciudadanos dueños de un inmueble, ya sea terreno, vivienda, despacho, oficina, edificio o local comercial. Este impuesto existe en muchos países del mundo y se sustenta en la idea de que todos aquellos que son propietarios de un bien inmueble, deben aportar una cuota anual al Estado en forma de tributo (Finanzas Prácticas, S/F).

El cobro de este impuesto, tiene su origen legal en la Constitución Política de los Estados Unidos Mexicanos, así como en el Código Municipal para el Estado de Chihuahua dentro del Código Fiscal para el Estado de Chihuahua. En ellos se establece como obligación a las personas propietarias de bienes inmuebles, pagar el impuesto por cada una de sus propiedades.

Como parte de la sistematización de la historia y el empuje municipal, desde hace no más de dos décadas, los gobiernos municipales han sido estudiados desde diferentes perspectivas. Estos estudios analizan la acción pública, la gobernabilidad en espacios urbanos, las experiencias innovadoras en municipios urbanos y sus debilidades institucionales, las experiencias de democratización, y la modernización en ciudades fronterizas. Sin embargo, todos los factores estudiados en dichos trabajos aseguran o suponen la necesidad de contar con recursos económicos suficientes para que el municipio cumpla con sus obligaciones y sea capaz de ejercer gasto de inversión para lograr tales innovaciones, modernización, y experiencias de gestión de los proyectos estudiados, aspecto que sin duda dimensiona el tema de la presente investigación. El importe del predial se destina para beneficio de toda la ciudadanía, ya que se utiliza en la mejora de la prestación de servicios públicos, en incrementar la inversión en obra pública y en los programas de tipo social. Una mayor recaudación de los ingresos derivados 
del impuesto predial dará como resultado un aumento en los ingresos propios y una mayor participación de los recursos federales (Puente \& Rodríguez, 2011).

Para el desarrollo de la presente investigación se decidió seguir la siguiente ruta: inicialmente se presentó un marco de referencia teórico, a continuación se definió el problema de investigación y objetivo; posteriormente se procedió a definir la hipótesis, se delinearon los criterios metodológicos adecuados, y se presentaron los resultados, lo cual permitió elaborar conclusiones y recomendaciones.

\section{MARCO DE REFERENCIA}

El origen de los tributos tiene sus indicios en la era primitiva, cuando el hombre entregaba ofrendas y primicias a los dioses a cambio de algunos beneficios. Se considera que los impuestos aparecen gracias a la religión, cuando el hombre paleolítico sentía la necesidad de atenuar sus temores o expresar agradecimiento a los dioses mediante sacrificios. Al transcurrir el tiempo, este tipo de dádivas se vuelven obligatorias, convirtiendo a la clase sacerdotal en la más poderosa, por ser el principal latifundista en el mundo medieval.

Durante la Edad Media en Europa, los pobladores producían vegetales o animales, apartando diezmos y primicias para la Iglesia Católica, así como los respectivos tributos al señor feudal (Labrada \& Rodríguez, 2010).

En México, la obligación de contribuir a los gastos del estado se remonta a las épocas del rey Azcapotzalco, quien pedía tributo a cambio de beneficios en su comunidad. Posteriormente, Hernán Cortés adoptó el sistema tributario del pueblo azteca, modificando la forma de cobro al cambiar los tributos de flores y animales por piedras y joyas. Durante el gobierno de Antonio López de Santa Anna se estableció el cobro de un Real de tributo por cada puerta y cuatro centavos por cada ventana, marcando el inicio del pago de impuesto por propiedad en el México moderno.

El impuesto predial es un tributo con el cual se grava una propiedad o posesión inmobiliaria. En México, el impuesto predial es controlado por los municipios de cada ciudad desde 1917 a partir del reconocimiento constitucional de los Municipios como nivel de gobierno.

La Tasa del Impuesto en México es acumulativa y progresiva variando entre $0.2 \%$ y $1 \%$, dependiendo del valor del predio (suelo, zona, etc.). El marco legal que regula el impuesto predial para el municipio de Chihuahua tiene su fundamento en la Constitución Política de los Estados Unidos Mexicanos (CPEUM) (Camara de Diputados LXIII Legislatura, 2015), el Código Fiscal de la Federación (CFF) (Diario Oficial de la Federación, 2014) y el Código Municipal para el Estado de Chihuahua (CMECH) (Congreso del Estado de Chihuahua, 2015). 
Por disposición constitucional los ciudadanos tienen como una de varias obligaciones contribuir con los gastos públicos de la Federación, así como del Distrito Federal o del Estado y Municipio en que residan, todo ello de la manera proporcional y equitativa que dispongan las leyes. Además, deben inscribirse en el catastro de la municipalidad manifestando las propiedades que tengan, lo cual faculta a los municipios para percibir las contribuciones sobre la propiedad inmobiliaria (Camara de Diputados LXIII Legislatura, 2015).

El marco legal vigente permite a los municipios establecer como base del impuesto predial el valor catastral del inmueble, de acuerdo al valor de mercado de las propiedades. A la vez, otorga al Fisco del Estado facultades para el cobro del Impuesto Predial y garantía real sobre el bien material del impuesto, dando prioridad a la acción fiscal del Estado sobre cualquier crédito de terceros, inclusive los fiscales federales (Congreso del Estado de Chihuahua, 2015).

En caso de que el contribuyente no pague el impuesto a tiempo, la autoridad está en la facultad de exigir a los contribuyentes el pago de recargos por la mora, recargos que se generarán hasta por cinco años. Si no se cubre el adeudo, la autoridad puede exigir su pago mediante el procedimiento administrativo de ejecución, el cual consiste en el embargo de bienes para cubrir el adeudo, los cuales podrán ser rematados para cubrir el crédito, los accesorios, gastos y vencimientos futuros según sea el caso (Congreso del Estado de Chihuahua, 2015).

El gobierno del Estado de Chihuahua y sus 54 municipios, entre ellos el municipio de Chihuahua, celebraron un convenio de colaboración administrativa para facultar al gobierno del estado a que lleve a cabo la cobranza coactiva a través del Procedimiento Administrativo de Ejecución, potenciando así la capacidad de cobro de los municipios.

\section{Impuesto Predial}

Una de las principales fuentes de ingreso en las administraciones municipales es sin lugar a duda el predial, el impuesto de periodicidad anual que grava el valor de los predios urbanos y rústicos. Dado que su recaudación depende de la calidad de gestión municipal, es necesaria la atención a esta importante área, pues los municipios tienen la obligación de recaudar fondos para satisfacer las necesidades de seguridad, salud, pavimentación, alumbrado y desarrollo social, entre otros (Ibarra \& Sotres, 2009).

En México, sólo cuatro de cada diez personas pagan el impuesto predial, lo cual afecta la recaudación fiscal y por ende a las finanzas públicas, ya que a pesar de que este impuesto tiene un potencial de recaudación de 250 mil millones de pesos, sólo se obtienen de él 31 mil 250 millones de pesos (Pedrero, 2015). 
La recaudación predial en México llama la atención por ser extremadamente baja en términos absolutos y relativos, pues en 2010 representó tan sólo $0.13 \%$ del PIB. En cambio, países como Reino Unido, Francia y Estados Unidos recaudan $4.2 \%, 3.7 \%$ y $3.1 \%$ de su PIB, respectivamente, mientras que países de ingresos similares a los mexicanos, como Argentina, Brasil, Colombia y Chile, recaudan 3\%, $2 \%, 1.5 \%$ y $0.7 \%$ de su PIB. A todas luces, la recaudación de este impuesto municipal en México es muy baja, lo que redunda en una hacienda local pobre y poco distributiva, además de reducir considerablemente la capacidad de los gobiernos municipales de asumir con eficacia las múltiples responsabilidades de gasto público que han ido asumiendo en los últimos treinta años (Unda \& Jaimes, 2015).

\section{Predial Chihuahua 2015}

El alcalde de la ciudad de Chihuahua anunció que el predial 2015 en Chihuahua tendría un incremento con respecto al del año anterior. En vista de que este aumento dependerá del presupuesto de egresos que se apruebe en Cabildo, aún no se puede precisar el porcentaje exacto. Se estima que el ajuste podrá rondar el 4\% para el año próximo (Los impuestos, 2015).

\section{Predial Chihuahua 2016}

Una encuesta realizada en el 2012 en el municipio de Parral, Chihuahua, analizó las diversas causas que motivan el problema del rezago anual en el pago del predial, a fin de romper con dicho comportamiento. Así lo expresó el licenciado, Jesús Gilberto Elías Ogaz, responsable de Catastro en el Municipio, quien mencionó que la estadística es clara y muestra un problema creciente (Ogaz, 2013).

Con base en los números, el entrevistado describió que durante el año 2008 el rezago anual fue de 6 millones de pesos, cifra que en 2009 subió a 8.5 millones, en 2010 a 12 millones, y en el 2011 a 14 millones. Cabe mencionar que el 98 por ciento de los deudores de cada uno de los años en cuestión, adeudan desde un peso hasta 20 mil.

Elías Ogaz reiteró que, dentro del análisis para buscar soluciones viables que frenen el rezago anual, se busca conocer las causas que generan la falta de pago de cada deudor. En la encuesta generada con tal finalidad se han incluido en primer lugar la evaluación del aspecto económico, en segundo lugar el tema legal, en tercero el factor comunicación y en cuarto lugar la forma de pago. De los resultados del análisis que se realiza deben surgir estrategias dirigidas a encontrar una solución, brindando mejores opciones al contribuyente para reducir el problema de falta de pago.

Entre las estrategias de apoyo que se han otorgado por la administración del período 2013-2016, se encuentran los descuentos directos 
al impuesto por pronto pago dentro de los tres primeros meses del año, y actualmente el descuento del 100 por ciento en los recargos del predial.

En la ciudad de Chihuahua, durante el 2014 se logró una captación superior al $20 \%$ en el impuesto predial, lo que representa 100 millones de pesos más de lo que se tenía contemplado al inicio del año. Esto permitió cerrar con más de 500 mdp, un logro "derivado del gran compromiso y responsabilidad ciudadana", dijo Garfio Pacheco (Ayuntamiento de Chihuahua, 2014).

\section{PROBLEMA DE INVESTIGACIÓN}

En los últimos años se ha incrementado el número de contribuyentes que no cumplen con el pago del impuesto predial en el municipio de Chihuahua, impactando con ello las finanzas municipales. En México, el estado de Chihuahua ocupa el quinto lugar en recaudación del impuesto predial, siendo la Ciudad de México, seguido por Quintana Roo, Nuevo León y Estado de México, los estados más exitosos en la recaudación mencionada (Arquitectura \& Urbanismo, 2016). Sin embargo, es necesario mencionar que en los municipios mexicanos no se han tenido buenos resultados en materia de recaudación del impuesto predial para generar ingresos propios que ayuden a sufragar el gasto público (Lux Consultores en Comercio y Desarrollo S.A de C.V., s/f). El estado de Chihuahua tiene 67 municipios, de los cuales los que obtienen mayores recursos por concepto de impuesto predial son los municipios fronterizos de Juárez y Janos, siendo los no fronterizos, como el municipio de Chihuahua, aquellos que están atrasados en la recaudación (Ibarra \& Sotres, 2014).

Específicamente, el rezago del impuesto predial en el municipio de Chihuahua al 31 de diciembre de 2014 era de $\$ 714,918,888.83$, cifra integrada por 143,348 cuentas,en donde no se llevó a cabo en su totalidad el Procedimiento Administrativo de Ejecución para su recuperación. Esto significa que sólo se elaboraron actas de notificación y determinación del crédito fiscal, mas no de la recuperación de los créditos fiscales rezagados (Auditoria Superior del Estado de Chihuahua, 2014).

En el municipio de Chihuahua, como ya se mencionó, existe un adeudo de $\$ 714,918,888.83$, presumiblemente porque no se aplica el Procedimiento Administrativo de Eecución. Se desconocen las razones por las cuales los causantes no hacen el pago en tiempo y forma, derivando de dicha situación las siguientes interrogantes:

1.- ¿Por qué hay contribuyentes que no cumplen con el pago de esta obligación?

2.- ¿El Municipio tiene implementado un programa para motivar a los contribuyentes morosos a actualizarse en el pago de este impuesto, o qué medidas se tienen establecidas? 
3.- ¿Existe en la población la cultura del no pago?

\section{OBJETIVO DEL ESTUDIO \\ Objetivo General}

Determinar las principales razones de rezago en el pago del Impuesto Predial del Municipio de Chihuahua.

\section{Objetivos Específicos}

Determinar si existe una cultura de no pago en los contribuyentes del municipio de Chihuahua.

\section{HIPÓTESIS}

La principal razón de rezago por parte de los contribuyentes en el pago del impuesto predial en el municipio de Chihuahua, es la falta de recursos económicos.

\section{CRITERIOS METODOLÓGICOS}

La naturaleza de la investigación fue cuantitativa y descriptiva, ya que se pretende extraer las generalizaciones más significativas del fenómeno que se estudia. El carácter de la investigación fue no experimental ya que no se manipuló la variable de estudio y se trabajó sobre situaciones o hechos ya existentes.

El diseño de la investigación fue de tipo no experimental transeccional, ya que la recolección de datos se llevó a cabo en un solo momento, y consistió en analizar a un grupo de personas que habitan en colonias cercanas a la plaza comercial Saucito. Las colonias que rodean esta plaza están densamente pobladas, ya que son una de las zonas de mayor crecimiento en la ciudad; las familias en un $75.24 \%$ son nucleares y el $24.97 \%$ de los hogares familiares tienen jefatura femenina. En cuanto a la tasa de participación económica (PE) es de 56.06; Los hombres presentan una mayor PE (70.78) en comparación con las mujeres (42.39) (Centros de Integración Juvenil, A.C, s/f).

La propuesta, en su etapa operativa, se apegó al método analíticosintético, no experimental, de investigación-acción y muestras, mediante encuestas con cuestionario y análisis cuantitativo estadístico. Todo ello dirigido a una población exclusivamente conformada por contribuyentes del impuesto predial de la ciudad de Chihuahua que presentan adeudo.

\section{Lugar y tiempo}

El trabajo de la investigación se llevó a cabo en la ciudad de Chihuahua en la plaza comercial denominada Saucito de octubre a diciembre del 2015. 


\section{Población}

La población de interés fueron los contribuyentes del impuesto predial de la ciudad de Chihuahua que presentan adeudo.

\section{Marco muestral}

El marco muestral fue tomando de la lista proporcionada por el Municipio del estado de Chihuahua, de la cuenta a contribuyentes deudores del impuesto predial de la ciudad.

\section{Unidad de análisis}

La unidad de análisis estuvo conformada por todas aquellas personas que sean propietarios de un bien inmueble y cumplan las siguientes características:

1.- Se encuentren ubicados en el área urbana de la ciudad de Chihuahua

2.- Acudan a la plaza de locales comerciales denominada Saucito

3.- Adeuden el impuesto predial

\section{Tamaño de la muestra}

Se calculó el tamaño de la muestra utilizando la fórmula para poblaciones infinitas o desconocidas. Se utilizó un nivel de confianza de 95\% y margen de error del 5\%, obteniendo una muestra de 375 encuestas.

\section{Poblaciones infinitas:}

$$
\mathbf{Z}_{\alpha}^{2} *(p)(\mathbf{q})
$$

\section{$\mathbf{i}^{2}$}

$\mathrm{n}=$ tamaño de muestra

$Z=$ nivel de confianza (95\%, convertida a desviación estandar, 1.96)

$\mathrm{i}=$ error de la estimación ( $5 \%$, expresado en decimales)

$p=$ éxito $(0.5)$

$q=$ fracaso $(0.5 ;$ la suma de $p$ y $q$ debe ser 1.0$)$

Con base en las características de la unidad de análisis, el muestreo que se aplicó fue probabilístico. La selección de la muestra, en función de los objetivos del estudio y considerando el tipo de muestreo seleccionado, fue aleatoria.

\section{INSTRUMENTOS DE INVESTIGACIÓN}

El instrumento de medición utilizado fue el Cuestionario "Análisis de la problemática en el cobro del Impuesto Predial del Municipio de Chihuahua" diseñado por los investigadores. La validez del instrumento se deriva de adecuar los contenidos abordados en las preguntas a las principales propuestas en la temática (validez de contenido). Para la validación de contenido, se utilizó el procedimiento de grupos conocidos (know groups), el cual se realizó 
en dos partes: una primera parte de revisión cualitativa y una segunda de revisión cuantitativa.

En la primera fase, se hizo una revisión detallada de las razones de no pago del impuesto predial por parte de tres expertos, quienes hicieron sugerencias que ayudaron a modificar redacción y justificar algunos ítems. En la segunda parte el instrumento, ya revisado cualitativamente, fue revisado de manera cuantitativa (valoración individual de 0 a 5) ítem por ítem, por otros tres expertos. En este proceso, se eliminaron aquellos ítems que obtuvieron una puntuación promedio inferior a 4,0. Al finalizar dicho proceso, quedó un instrumento conformado por 13 ítems.

\section{RESULTADOS}

El instrumento de medición tiene dos preguntas significativas: ¿Es usted contribuyente del Impuesto Predial? ¿Tiene algún adeudo con la Presidencia Municipal por concepto del Impuesto Predial? Si la respuesta a ambas preguntas es afirmativa, el sujeto es candidato a la aplicación del cuestionario de investigación, a fin de determinar las razones por las que tiene adeudo con la Presidencia Municipal.

A continuación, se presentan los resultados de las preguntas del instrumento por medio de gráficas.

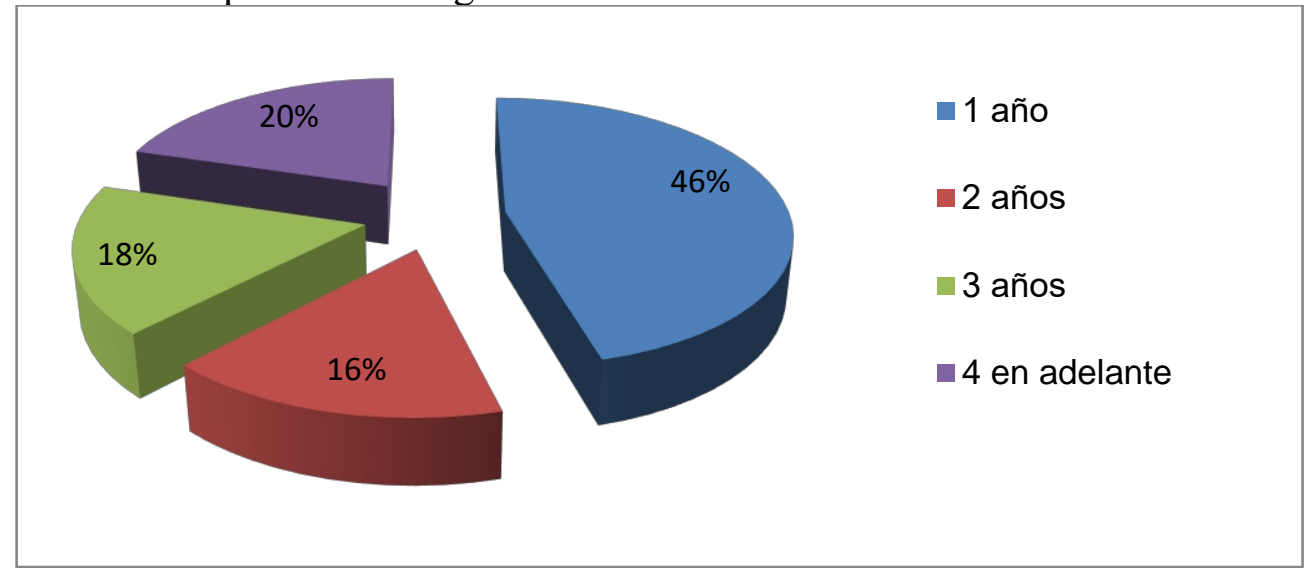

Gráfica No. 1 ¿Desde cuándo tiene el adeudo con la presidencia municipal por concepto de predial?

Fuente: elaboración propia

La presente gráfica permite afirmar que el mayor porcentaje de deudores se encuentra en la categoría de un año con el 46\%; en segunda instancia, con un $20 \%$ deudores, se encuentran aquellos con cuatro años o más de adeudo, seguido por un $18 \%$ de deudores con tres años de adeudo, y por último un $16 \%$ con un rezago de dos años. En México sólo cuatro de cada diez personas pagan el impuesto a la propiedad, conocido como predial, lo cual afecta la recaudación fiscal y por ende a las finanzas (Pedrero, 2015). 


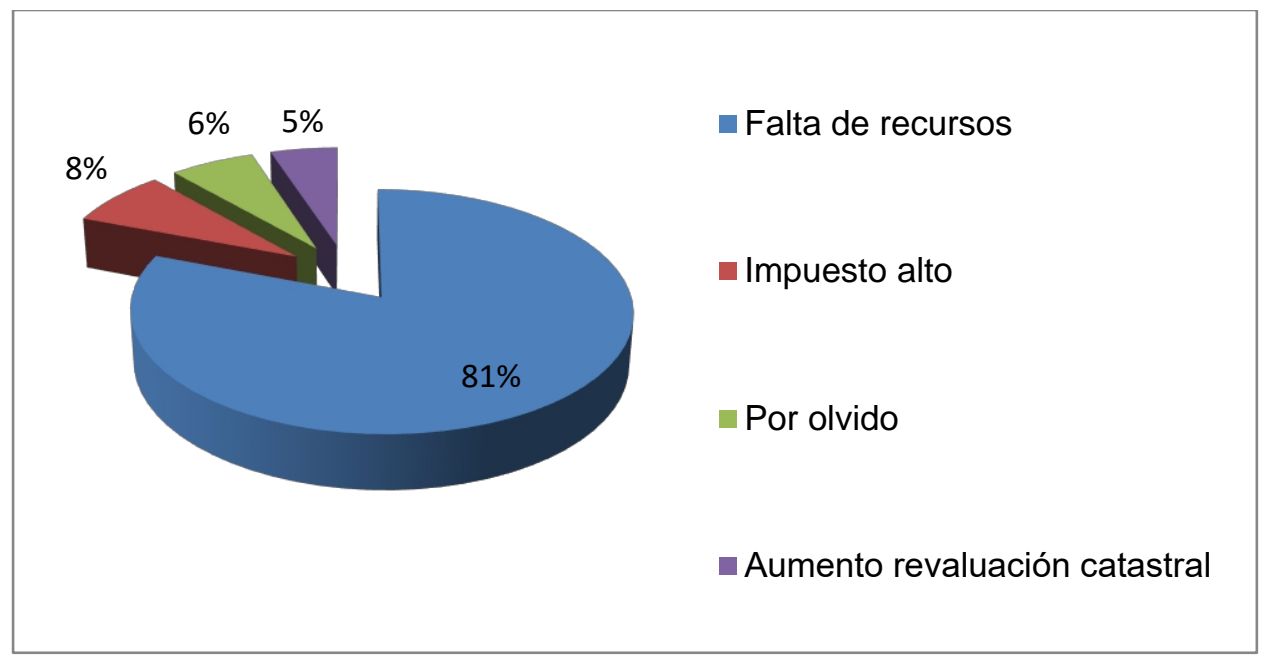

Gráfica No. 2 ¿Por qué razón no ha cumplido con la obligación de pagar el impuesto predial?

Fuente: elaboración propia

Con la finalidad de conocer por qué no han cumplido con el pago, de 375 encuestas realizadas se obtuvo que el $81 \%$ no paga impuesto predial por falta de recursos económicos; un $8 \%$ lo considera un impuesto alto; al $6 \%$ se le olvida pagar y el $4 \%$ lo atribuyó a un aumento por revaluación catastral.

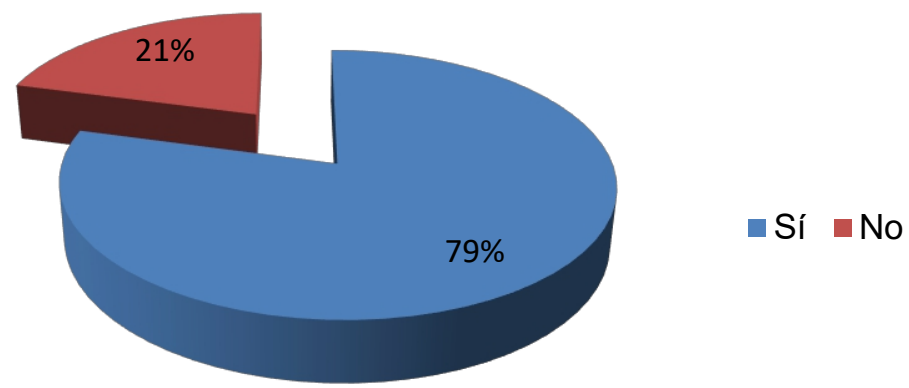

\section{Gráfica No. 3 ¿Ha recibido estados de cuenta o gestiones de cobro por parte del departamento de catastro municipal?}

Fuente: elaboración propia

De los 375 encuestados, el $79 \%$ manifiesta haber recibido estados de cuenta y gestiones de cobro por parte del área de catastro municipal, mientras que el $21 \%$ no ha recibido ningún tipo de cobro o recordatorio de pago. La optimización de herramientas técnicas y el tratamiento de la base imponible del impuesto, en conjunto con el estudio de la estructura urbana e inmobiliaria 
asociadas, resultan relevantes para su diseño y puesta en marcha (Mier torres, 2012).

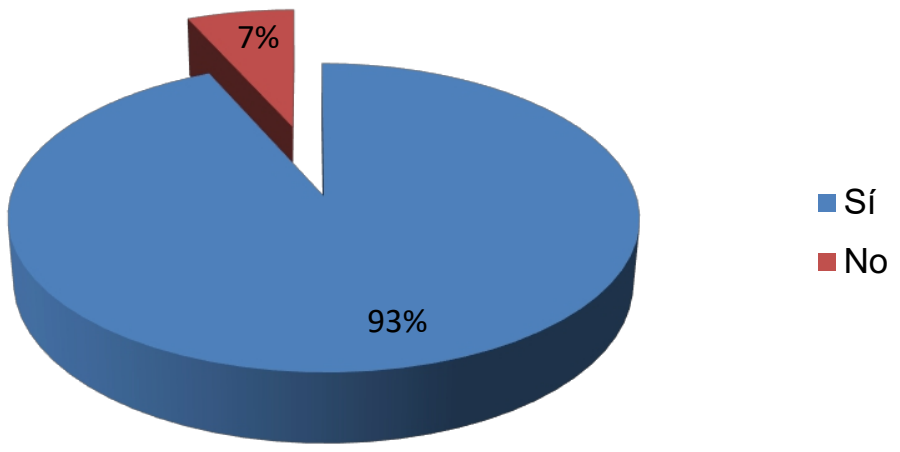

Gráfica No. 4 ¿Tiene conocimiento de que el pago del impuesto predial es obligatorio y que la Presidencia Municipal, a través del Departamento de Catastro, cuenta con facultades para exigirle el pago de su adeudo por la vía legal?

Fuente: elaboración propia

E1 93\% manifestó que sí tenía conocimiento de las facultades que tiene la presidencia municipal para exigir el pago del impuesto predial por la vía legal; sólo el 7\% tiene desconocimiento de ello.

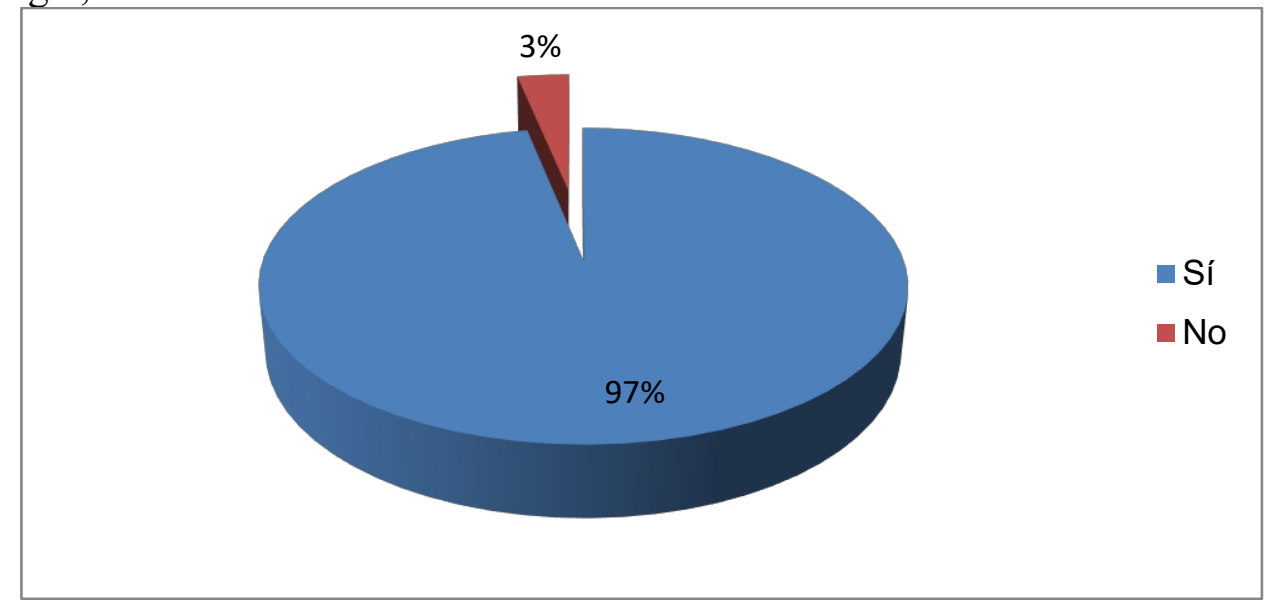

Gráfica No. 5 ¿Tiene conocimiento de los lugares en los que puede realizar el pago del impuesto predial?

Fuente: elaboración propia

El 97\% de los encuestados sí conoce los diversos lugares donde se puede realizar el pago de este impuesto. E1 3\% declaró desconocimiento sobre esto, mencionando que sólo conocen el lugar ubicado en las calles 6ta y Mina. 
Sin embargo, también podrían pagar el gravamen en las tesorerías municipales, recaudaciones de rentas, centros comerciales, bancos e internet (Amaro, 2014).
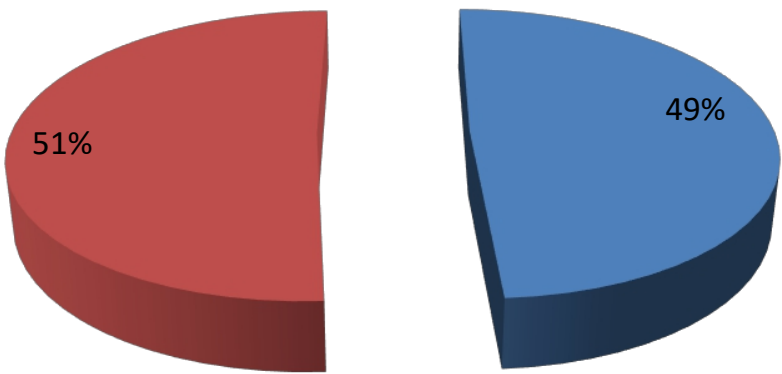

Gráfica No. 6 ¿Está conforme con el valor de impuesto otorgado por el Departamento de Catastro municipal a su propiedad?

Fuente: elaboración propia

De la gráfica se desprende que el $51 \%$ no está conforme con el valor del impuesto establecido por el departamento de catastro municipal y el $49 \%$ manifestó estar satisfecho con el monto asignado.

A raíz de la reforma constitucional al Artículo 115 (1999), los municipios fueron dotados de atribuciones para proponer a la legislatura local tanto las tablas de valores unitarios para suelo y construcción, como las tasas y tarifas para el cobro del impuesto predial, entre otras facultades (Ibarra \& Sotres, Diferencias en la recaudación del impuesto predial en la zona fronteriza. Evidencia en los municipios de Chihuahua., 2014).

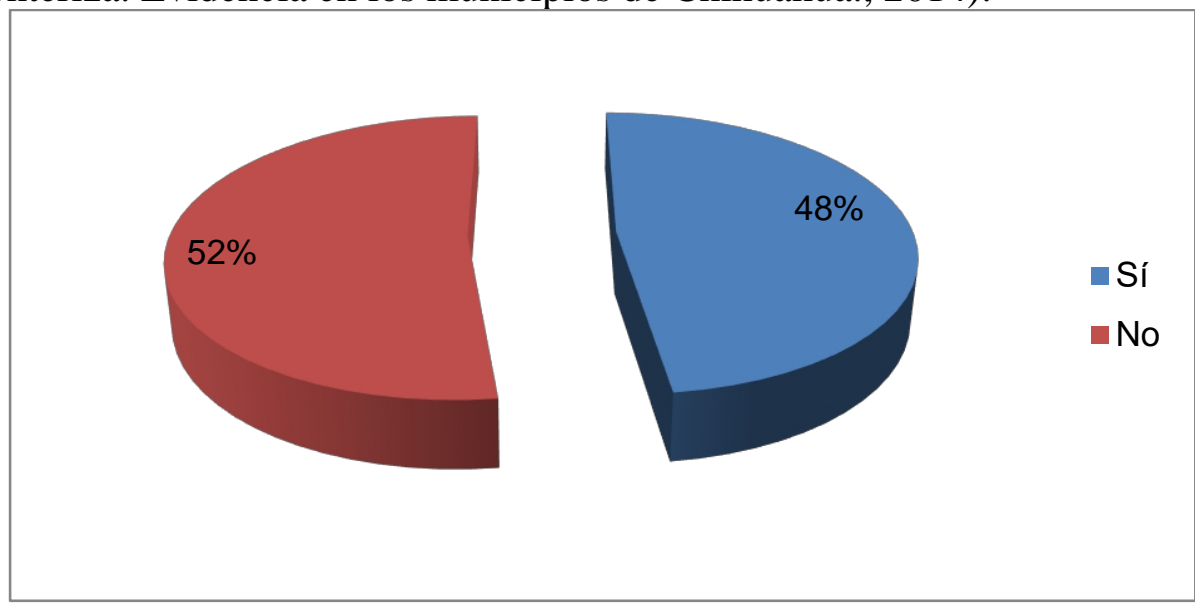

Gráfica No. 7 ¿Considera justo el impuesto predial que paga por su propiedad?

Fuente: elaboración propia 
El 52\% no considera justo el impuesto que debe pagar por su propiedad, mientras que el $48 \%$ está totalmente de acuerdo con el impuesto asignado. Esto dio lugar a que los municipios que así lo decidieran hicieran uso de estas atribuciones para actualizar los valores catastrales de los predios, modificar las tasas y tarifas, e implementar programas para hacer más eficiente la recaudación (Ibarra \& Sotres, Diferencias en la recaudación del impuesto predial en la zona fronteriza. Evidencia en los municipios de Chihuahua., 2014).

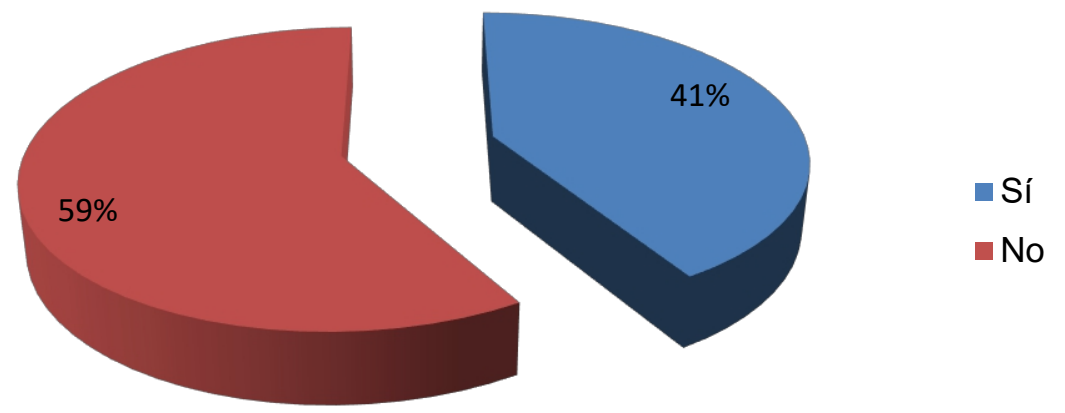

Gráfica No. 8 ¿Usted considera que lo que paga de predial realmente se ve reflejado en servicios que proporciona la Presidencia Municipal a través de los diferentes departamentos?

Fuente: elaboración propia

A partir de la gráfica se determina que el $59 \%$ de los encuestados no ve reflejado en los servicios que proporciona la presidencia municipal los pagos efectuados y el $41 \%$ manifiesta sí ver expresado el pago de este impuesto en los servicios prestados por el municipio.

Es necesario contar con recursos económicos suficientes para que el municipio cumpla con sus obligaciones y cuente con recursos suficientes a fin de ejercer gastos de inversión para lograr tales innovaciones, modernización y experiencias de gestión de los proyectos estudiados (Puente \& Rodríguez, 2011). 


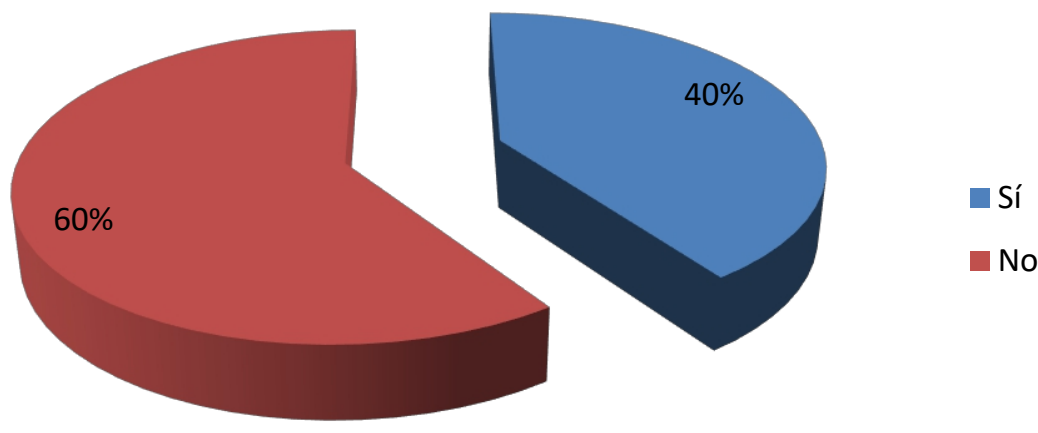

Gráfica No. 9 ¿Tiene conocimiento del destino que da la Presidencia Municipal a los recursos provenientes del impuesto predial?

Fuente: elaboración propia

Se obtuvo que el $60 \%$ de la población tomada como muestra desconoce el destino que la presidencia municipal da a los recursos provenientes del pago del impuesto predial y, en menor proporción, el $40 \%$ dice sí conocer en qué conceptos se utilizan.

Consecuentemente podemos decir que, debido a este alto índice de deuda y la poca recaudación del área de Administración Tributaria, no se realizarán las inversiones destinadas para la ejecución de proyectos de obras de importancia o prioridad (Ibarra \& Sotres, 2009).

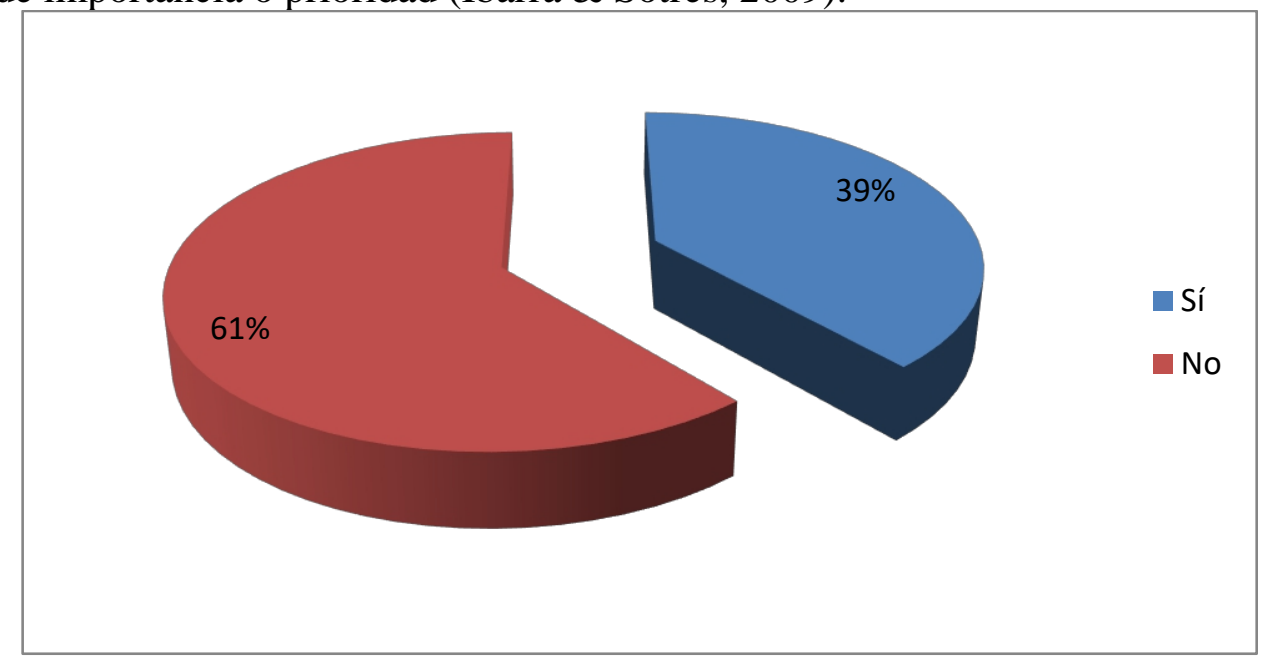

Gráfica No. 10 Conoce qué tipos de servicios otorga la Presidencia Municipal con los recursos recaudados del impuesto predial?

Fuente: elaboración propia 
De los 375 entrevistados, el $61 \%$ manifiesta no conocer los tipos de servicios que se proporcionan por el municipio con estos recursos recaudados, mientras que el 39\% sí está enterado de todos los servicios proporcionados.

La recaudación es limitada a pesar de que el objetivo básico de todo sistema tributario es generar los recursos suficientes para financiar el abastecimiento de bienes y servicios públicos (Puente \& Rodríguez, 2011).

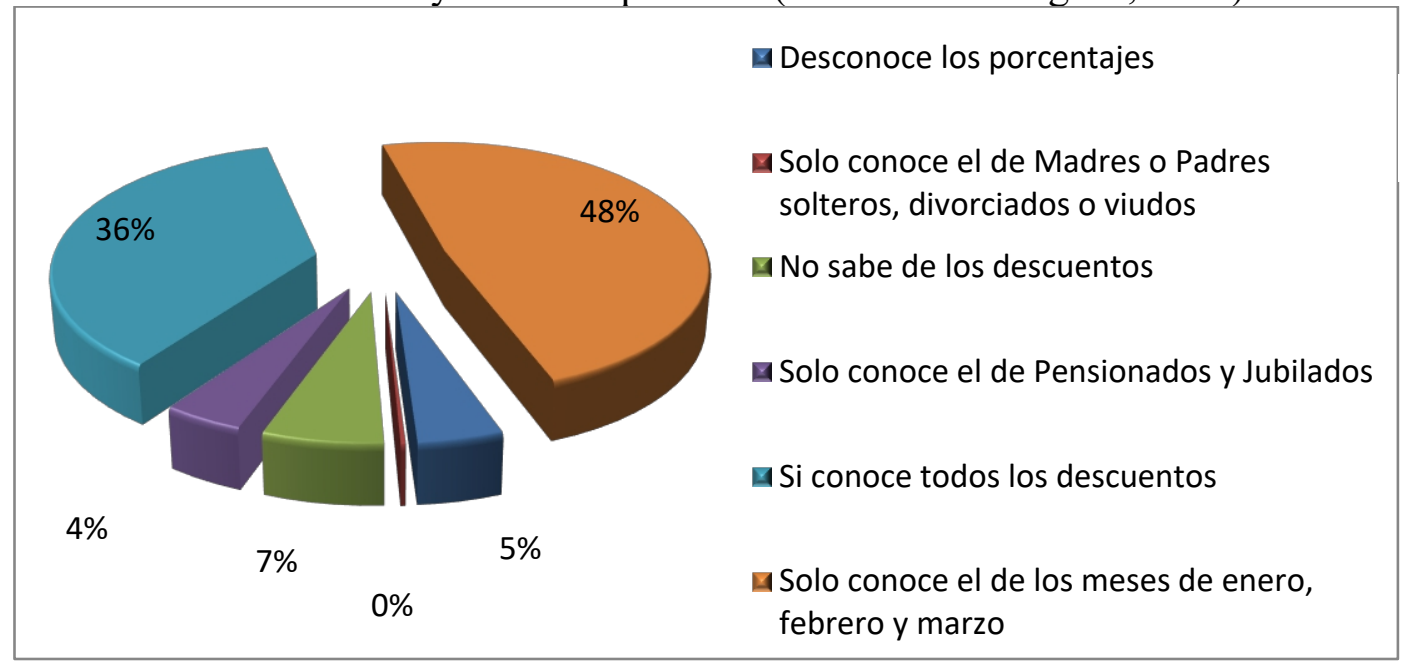

Gráfica No. 11 ¿Conoce los diferentes tipos de descuentos que otorga la Presidencia Municipal para el pago del impuesto predial?

Fuente: elaboración propia

En relación a si las personas conocen los diferentes descuentos otorgados por el pago del predial, el $48 \%$ sólo conoce los descuentos que se hacen por pago anticipado en los meses de enero, febrero y marzo de cada año; el 36\% sí conoce todos los descuentos que se otorgan; el $7 \%$ no sabe de los descuentos otorgados; el 5\% sabe de los descuentos pero desconoce los porcentajes para cada concepto y el $4 \%$ sólo conoce los que se efectúan a pensionados y jubilados. El Presidente Municipal de Chihuahua, Javier Garfio, conminó a la población a realizar sus pagos a tiempo, beneficiándose de los descuentos que se ofrecen (Ayuntamiento de Chihuahua, 2014; Metros cúbicos, 2014).

En base al análisis de los resultados y siguiendo la secuencia lógica de la investigación, se obtuvieron las respuestas a las preguntas de investigación, la comprobación de la hipótesis y el cumplimiento de los objetivos planteados.

Con relación a la situación del cobro del impuesto predial y a la cultura de no pago entre los contribuyentes en el municipio de Chihuahua al 31 de diciembre de 2014, se tiene un importe pendiente de cobro por $\$ 714,918,888.33$, integrado por 143,348 cuentas. De acuerdo a los resultados, en torno a la pregunta donde se mencionaba si los contribuyentes morosos han recibido estados de cuenta o gestiones de cobro por parte del departamento de 
catastro municipal, el $79 \%$ manifiesta haber recibido estados de cuenta y gestiones de cobro por parte del área de catastro municipal, mientras que el $21 \%$ no ha recibido ningún tipo de cobro o recordatorio de pago. De igual manera, se identificó que el municipio tiene implementado un programa de reducción por pronto pago; sin embargo, se determinó que no se le ha dado la suficiente difusión, ya que de los encuestados sólo el 36\% conoce todos los descuentos que se otorgan. En base a lo anterior se infirió que el sistema para el cobro del rezago de pago del impuesto predial puede mejorar en cuanto a comunicación y aplicación de las facultades de la Presidencia Municipal a través del Departamento de Catastro para exigir el pago del adeudo por la vía legal.

Derivado de la investigación, se llegó a la conclusión de que el 6\% de los encuestados tiene este tipo de hábito (gráfica No. 2), mientras que el 94\% tienen intención de pagar, sin embargo, principalmente por cuestiones económicas, no se han puesto al corriente del adeudo de este impuesto.

En base a los resultados, se logró visualizar que la principal causa por la que los contribuyentes deudores no pagan el impuesto es por falta de recursos económicos. Por lo tanto, no se logró rechazar la hipótesis planteada.

\section{CONCLUSION}

En relación a loantes expuesto, se identificó la necesidad de que la Presidencia Municipal inicie acciones más eficientes de comunicación en torno a los lugares en donde los contribuyentes pueden pagar, así como de los beneficios que se obtienen al pagar anticipadamente este impuesto. Adicionalmente, se considera necesario implementar medidas de cobro alineadas a las necesidades de los contribuyentes. Con el apoyo de trabajadores sociales sería posible realizar estudios socioeconómicos y una valorización objetiva de la situación económica de cada núcleo familiar, para de esta manera determinar la situación real de pago del contribuyente.

Aún y cuando el municipio lleva a cabo ciertas medidas para la recuperación del impuesto predial, éste debe buscar acciones correctivas y mecanismos más efectivos para la recuperación del impuesto rezagado.

Es necesario que la Presidencia Municipal informe por colonias y/o sectores los ingresos que estima recaudar por cada uno, así como el uso/aplicación de los recursos. Los gobiernos exitosos son los que logran mejorar su capacidad recaudatoria y reflejan ésta en más y mejores servicios de seguridad, salud, pavimentación, alumbrado y desarrollo social, entre otros.

Finalmente, la concientización y sensibilización de los ciudadanos se logra con la efectiva utilización de los medios como: televisión, radio, redes sociales, medios digitales y escritos. Esto impulsará la participación y apoyo de los ciudadanos. 


\section{References:}

1. Amaro, J. J. (31 de diciembre, 2014). Chihuahua cobrará a Municipios predial a partir del 5 de enero. Milenio.

2. Arquitectura \& Urbanismo. (2016). Propiedades.comblog. Recuperado el 3 de 6 de 2018, de Impuesto predial en México: sin recaudación no hay beneficios: http://propiedades.com/blog/arquitecura-y-urbanismo/impuestopredial-em-mexico

3. Auditoría Superior del Estado de Chihuahua. (31 de octubre, 2014). Auditoría Superior Chihuahua. Recuperado noviembre 2015 de Informe técnico de resultados 2014: http://www.auditoriachihuahua.gob.mx/abierta/sites/default/files/CA TI\%20ITR\%20Chihuahua.pdf

4. Ayuntamiento de Chihuahua. (31 de diciembre, 2014). Ayuntamiento de Chihuahua. Recuperado 8 de noviembre 2015 de Municipio de Chihuahua: http://www.municipiochihuahua.gob.mx/Gobierno/Noticia/4658

5. Cámara de Diputados LXIII Legislatura. (2015). Constitución Política de los Estados Unidos Mexicanos. (D. O. Federación, Ed.) Obtenido de última reforma publicada D.O.F. 27-01-2016: http://www.diputados.gob.mx/LeyesBiblio/htm/1.htm

6. Centros de Integración Juvenil, A.C. (s/f). Estudio Básico de Comunidad Objetivo. Recuperado el 7 de 06 de 2018, de Diagnóstico del contexto socio-demofráfico del área de Influencia del CIJ Chihuahua: http://www.cij.gob.mx/ebco2013/centros/9720SD.html

7. Congreso del Estado de Chihuahua. (2015). Código Municipal para el Estado de Chihuahua. Obtenido de última reforma POE 2015.10.24/No.85:

http://www.congresochihuahua.gob.mx/biblioteca/codigos/archivosC odigos/19.pdf

8. Congreso del Estado de Chihuahua. (2015). Código Fiscal del Estado de Chihuahua. Obtenido de última reforma POE 2015.04.29/No. 34: http://www.congresochihuahua.gob.mx/biblioteca/codigos/archivosC odigos/29.pdf

9. Diario Oficial de la Federación. (2014). Reglamento del Código Fiscal de la Federación. Obtenido de http://www.dof.gob.mx/nota_detalle.php?codigo $=5339148 \&$ fecha $=0$ 2/04/2014

10. Finanzas Prácticas. (S / F). El pago del impuesto Predial. Recuperado el 28 de octubre de 2015 de https://finanzaspracticas.com.mx/finanzaspersonales/etapas-de-la-vida/alquiler-o-compra-de-vivienda/el-pagode-impuesto-predial 
11. Ibarra, J. \& Sotres, L. (2009). Determinantes de la recaudación del impuesto predial en Tamaulipas: Instituciones y zona frontera norte. Frontera Norte , 21 (42), 165-192.

12. Ibarra, J. \& Sotres, L. (2014). Diferencias en la recaudación del impuesto predial en la zona fronteriza. Evidencia en los municipios de Chihuahua. Estudios Demográficos y Urbanos , 29 (1), 53-87.

13. Labrada, M. \& Rodríguez, L. (2010). La explotación de los recursos naturales y la protección del medio ambiente en las regulaciones jurídicas tributarias cubanas. Habana, Cuba: Universidad Oscar Lucero Moya de Holguín. Metros cúbicos. (30 de diciembre, 2014). Qué es el impuesto predial. Recuperado el 5 de noviembre 2015 de Metros cúbicos: http://www.metroscubicos.com/articulo/consejos/2012/10/02/que-esel-impuesto-predial

14. Los impuestos. (3 de noviembre, 2015). Impuesto Predial 2015. Recuperado el 5 de noviembre 2015 de Los impuestos: http://losimpuestos.com.mx/predial/\#Cuales-serian-los-beneficios-de8220Vamonos-en-Grupo8221

15. Lux Consultores en Comercio y Desarrollo S.A de C.V. (s/f). Centro de Estudios de las Finanzas Públicas. Recuperado el 3 de 6 de 2018, de Impuesto Predial, análisis y alternativas para mejorar la capacidad recaudatoria en los municipios de México: http://www.cefp.gob.mx/transp/CEFP-CEFP-70-41-C-Estudio0009010617.pdf

16. Mier torres, H. (2012). El impuesto predial urbano: Análisis teórico y aproximación inicial al caso de la ciudad de Caracas. Revista de Ciencias Sociales, Facultad de ciencias económicas y sociales, 18 (3), 416-419.

17. Ogaz, J. A. (20 de julio de 2013). El Monitor de Parral. Recuperado el 7 de noviembre de 2015, de http://www.elmonitorparral.com/notas.pl? $\mathrm{n}=46353$

18. Pedrero, E. (5 de enero, 2015). Sólo 4 de cada 10 mexicanos paga impuesto predial: Imco. La Razón.

19. Puente, J. \& Rodríguez, R. (2011). Estimación del potencial de recaudación de las haciendas locales: Un enfoque de fronteras estocásticas. Finanzas Públicas, 3 (6), 279-322.

20. Unda, G. M. \& Jaimes, C. M. (2015). La Recaudación del Impuesto Predial en México: Un análisis de sus determinantes económicos en el período 1969-2010. 2015. Revista Mexicana de Ciencias Políticas y Sociales, $53-84$ 